This item was submitted to Loughborough's Research Repository by the author.

Items in Figshare are protected by copyright, with all rights reserved, unless otherwise indicated.

\title{
Generation of low-frequency ground vibrations by sound waves propagating in underground gas pipes
}

\section{PLEASE CITE THE PUBLISHED VERSION}

http://www.multi-science.co.uk/lowfreq.htm

\section{PUBLISHER}

(c) Multi-Science Publishing

VERSION

VoR (Version of Record)

\section{LICENCE}

CC BY-NC-ND 4.0

\section{REPOSITORY RECORD}

Krylov, Victor V.. 2012. "Generation of Low-frequency Ground Vibrations by Sound Waves Propagating in Underground Gas Pipes”. figshare. https://hdl.handle.net/2134/10043. 
This item was submitted to Loughborough's Institutional Repository (https://dspace.lboro.ac.uk/) by the author and is made available under the following Creative Commons Licence conditions.

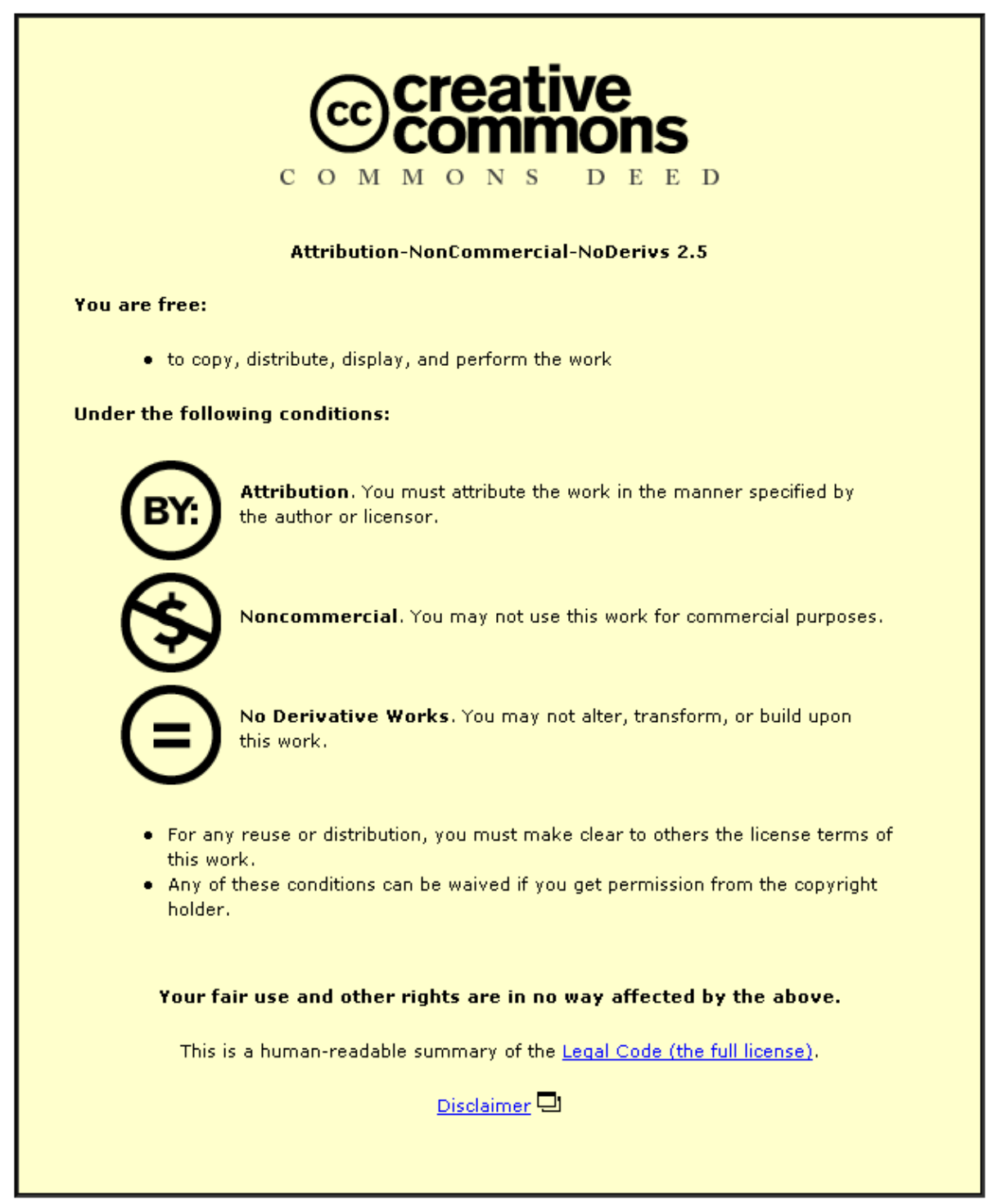

For the full text of this licence, please go to: http://creativecommons.org/licenses/by-nc-nd/2.5/ 
Generation of Low-Frequency Ground Vibrations by Sound Waves Propagating in Underground Gas Pipes

\author{
by \\ V.V. Krylov \\ Reprinted from \\ JOURNAL OF \\ LOW FREQUENCY \\ NOISE \& VIBRATION
}

VOLUME 14 No. 31995

MULTI-SCIENCE PUBLISHING CO. LTD.

107 High Street, Brentwood, Essex CM14 4RX, United Kingdom 


\title{
Generation of Low-Frequency Ground Vibrations by Sound Waves Propagating in Underground Gas Pipes
}

\author{
V.V. Krylov \\ Centre for Research into the Built Environment, Nottingham Trent University, \\ Burton Street, Nottingham NGI $4 B U, U K$
}

Received 25 February, 1995

The hypothesis is examined about sources of disturbing low-frequency hums arising from buried gas or petrol pipes in which turbulent flows of gas or liquid generate sound waves of high amplitude propagating in pipe-lines as in waveguides. Theoretical investigation of this problem shows that if the velocities of sound inside the pipes $(450 \mathrm{~m} / \mathrm{s}$ for methane) are higher than the velocities of Rayleigh surface waves in the ground (typically $300-600 \mathrm{~m} / \mathrm{s}$ ) then ground Rayleigh waves are effectively generated by sound waves propagating inside the pipes, the mechanism of generation being similar to that of sonic boom from supersonic jets. The Rayleigh waves then propagate to buildings and cause building vibration and structure-borne noise. Central frequencies of generated Rayleigh wave spectra are in the range of $5-20 \mathrm{~Hz}$ and depend on pipe-depth. The amplitudes of ground vibration velocity may achieve $70 \mathrm{~dB}$ (relative to $10^{-9} \mathrm{~m} / \mathrm{s}$ ). This is quite enough to annoy some people both due to the direct impact of vibrations and to structure-borne noise. The results obtained may contribute to a fuller understanding of the nature of low-frequency hums.

\section{INTRODUCTION}

The problem of disturbing low-frequency noise and vibration, also called lowfrequency hum, has been known in the UK for at least two decade ${ }^{1,2}$. However, in many aspects the nature of this low-frequency hum remains a mystery (see, e.g., The Independent of 22 June 1994). This is why further theoretical and experimental research into the low-frequency hum is necessary, with emphasis on a fuller understanding of its physical nature.

There might be different mechanisms of the hum. In our opinion, one such mechanism may be related to structure-borne sound caused by ground vibrations propagating to buildings as surface Rayleigh waves ${ }^{3-5}$ (this might be one of the reasons why the sources of the low-frequency hum are so difficult to identify by traditional acoustic measurements carried out to date). In the present paper we analyse the possibility of surface wave sources being buried underground gas or petrol pipes in which turbulent flows of gas or liquid generate sound waves of high amplitude propagating in a pipe-line as in a waveguide. The velocities of sound, $\mathrm{c}_{0}$, inside the pipes $(450 \mathrm{~m} / \mathrm{s}$ for methane) may be often higher than the velocities of Rayleigh surface waves, $c_{R}$, in the ground at the frequencies of interest $(5-50 \mathrm{~Hz})$. Typical values of $c_{R}$ are $300-$ $600 \mathrm{~m} / \mathrm{s}$. If $c_{0}>c_{R}$, then ground Rayleigh waves are expected to be effectively 
generated by sound waves propagating inside the pipes. The physical nature of this phenomenon is similar to that of sonic boom from supersonic jets or the recently predicted Rayleigh ground wave boom from superfast trains ${ }^{4,5}$.

In what follows we demonstrate that central frequencies of generated Rayleigh wave ground vibration spectra depend on the depth of the pipe and are in the low-frequency range $(5-20 \mathrm{~Hz})$. The amplitudes of generated ground vibration velocity due to sound waves propagating in gas pipes buried at a depth from one to two metres may achieve $70 \mathrm{~dB}$ (relative to $10^{-9} \mathrm{~m} / \mathrm{s}$ ). This is high enough to annoy some people both because of the direct impact of vibrations and due to generated structure-borne noise.

\section{THEORETICAL MODEL}

Let us assume that a gas or petrol pipe of radius a and wall thickness $d$ is buried at a depth $\mathrm{h}$ (Figure 1) and consider propagation of a time-harmonic sound wave inside this pipe (the lowest waveguide mode):

$$
\mathrm{p}(\mathrm{x}, \mathrm{t})=\mathrm{p}_{0} \exp \left[\mathrm{i}\left(\mathrm{k}_{0} \mathrm{x}-\omega \mathrm{t}\right)\right]
$$

Here $\mathrm{p}(\mathrm{x}, \mathrm{t})$ is time- and space-dependent sound pressure, $\mathrm{p}_{0}$ is the sound pressure amplitude, $\mathrm{k}_{0}=\omega / \mathrm{c}$ is the sound wavenumber, $\omega=2 \pi \mathrm{f}$ is the angular frequency, and $\mathrm{c}_{0}$ is the velocity of sound in the pipe gas (for certainty we limit our discussion to gas pipes only). We recall that the total pressure inside the pipe is $P(x, t)=P_{s t}+p(x, t)$, where $P_{s t}$ is a static pressure. The sources of sound wave excitation inside pipes may be different. It may be, for example, powerful compressors in gas compressor stations or instabilities of a gas flow in a pipe itself. We will not discuss these mechanisms here, considering the sound amplitude $\mathrm{p}_{0}$ as given value.

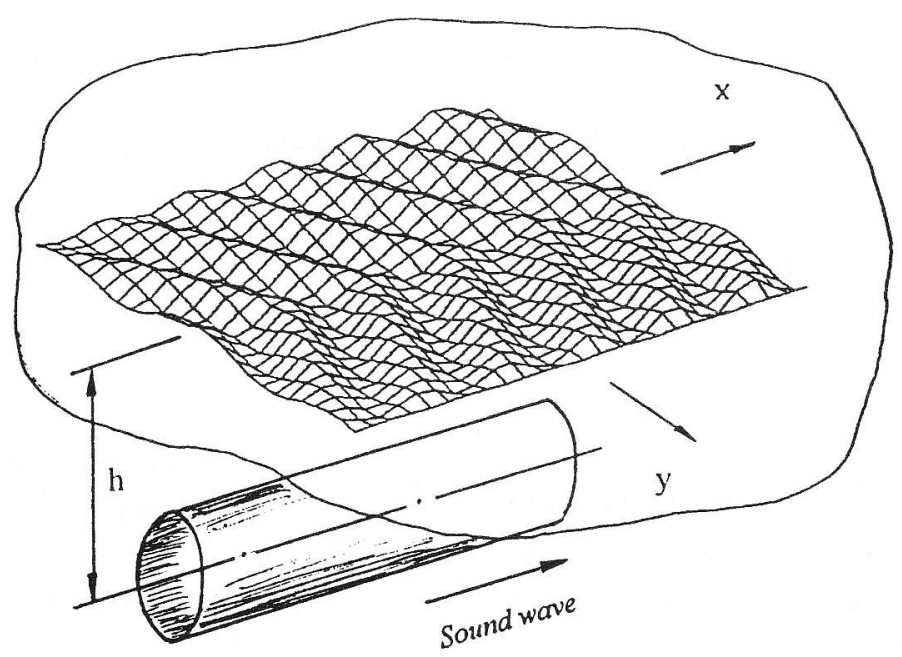

Figure 1. Geometry of the problem showing generated ground vibrations.

Propagation of a sound wave in the pipe causes displacements of the pipe walls which in turn can generate elastic waves in the adjacent ground. Ignoring the effect of the ground on pipe deformations and using the quasi-static solution of thin shell equations ${ }^{6,7}$, one can obtain the expressions for radial and horizontal displacements of the pipe walls respectively 


$$
\begin{gathered}
w=\left(a^{2} / E d\right) p(x, t) \\
v=i\left(a \sigma / E d k_{0}\right) p(x, t)
\end{gathered}
$$

where E and $\sigma$ are Young's modulus and Poisson's ratio of the pipe material.

The next step in the solution is to determine the amplitudes of the elastic fields generated in the bulk of the ground due to the displacements of pipe walls (2), (3). Introducing cylindrical coordinates $\mathrm{r}$, $\mathrm{x}$ associated with the pipe axis, we can express radial and horizontal displacements in the ground in terms of the elastic potentials $\varphi$ and $\psi$ :

$$
\begin{gathered}
u_{r}=\partial \varphi / \partial r+\partial^{2} \psi / \partial r \partial x \\
u_{x}=\partial \varphi / \partial x-\partial^{2} \psi / \partial r^{2}-(1 / r) \partial \psi / \partial r
\end{gathered}
$$

The quantities $\varphi$ and $\psi$ describe the potential and vortex parts of the elastic field respectively and satisfy the wave equations

$$
\begin{aligned}
& \Delta \varphi-\left(1 / c_{1}\right) \partial^{2} \varphi / \partial t^{2}=0 \\
& \Delta \psi-\left(1 / c_{t}\right) \partial^{2} \psi / \partial t^{2}=0
\end{aligned}
$$

where $\Delta=\partial^{2} / \partial \mathrm{r}^{2}+(1 / \mathrm{r}) \partial / \partial \mathrm{r}+\partial^{2} / \partial \mathrm{x}^{2}$ is the Laplace differential operator written in cylindrical coordinates, $c_{1}$ and $c_{t}$ are the velocities of longitudinal and shear bulk waves in the ground. On the pipe walls, i.e., at $r=a$, the displacements of the ground $\mathrm{u}_{\mathrm{r}}$ and $\mathrm{u}_{\mathrm{x}}$ should satisfy the boundary conditions

$$
\mathrm{u}_{\mathrm{r}}=\mathrm{w} \text { and } \mathrm{u}_{\mathrm{x}}=\mathrm{v}
$$

where $\mathrm{w}$ and $\mathrm{v}$ are determined by (2), (3).

The solution of the boundary value problem (2)-(8) is sought in the form

$$
\begin{aligned}
& \varphi=\mathrm{AH}_{0}^{(1)}\left(\mathrm{v}_{1} \mathrm{r}\right) \exp \left[\mathrm{i}\left(\mathrm{k}_{0} \mathrm{x}-\mathrm{i} \omega \mathrm{t}\right)\right] \\
& \psi=\mathrm{B} \mathrm{H} \mathrm{H}_{0}^{(1)}\left(\mathrm{v}_{\mathrm{t}} \mathrm{r}\right) \exp \left[\mathrm{i}\left(\mathrm{k}_{0} \mathrm{x}-\mathrm{i} \omega \mathrm{t}\right)\right]
\end{aligned}
$$

where $\mathrm{H}_{0}^{(1)}\left(\mathrm{v}_{1, \mathrm{t}} \mathrm{r}\right)$ is the Hankel function of the first kind and zero order, $\mathrm{v}_{1, \mathrm{t}}=$ $\left(\mathrm{k}_{1, \mathrm{t}}{ }^{2}-\mathrm{k}_{0}{ }^{2}\right)^{1 / 2}, \mathrm{k}_{1}=\omega / \mathrm{c}_{1}$ and $\mathrm{k}_{\mathrm{t}}=\omega / \mathrm{c}_{\mathrm{t}}$ are the wavenumbers of longitudinal and shear bulk waves, A and B are as yet unknown coefficients. Note that (9), (10) satisfy the equations (6), (7) respectively. Obviously, if $\mathrm{k}_{1, \mathrm{t}}{ }^{2}>\mathrm{k}_{0}^{2}$, then $\varphi$ and $\psi$ in (9), (10) describe conical longitudinal and shear elastic waves propagating away from the pipe. In the opposite case, $\mathrm{k}_{1, \mathrm{t}}{ }^{2}<\mathrm{k}_{0}^{2}$, expressions (9), (10) describe localised quasi-static fields travelling along the pipe at speed $c_{0}$.

Coefficients $\mathrm{A}$ and $\mathrm{B}$ are determined from the boundary conditions (8). Using the low-frequency approximation for the Hankel function $\mathrm{H}_{0}^{(1)}\left(\mathrm{v}_{\mathrm{l}, \mathrm{r}} \mathrm{r}\right)=$ $(2 \mathrm{i} / \pi) \ln \left(\mathrm{v}_{1, \mathrm{t}} \mathrm{r}\right)$ valid for $\mathrm{v}_{1, \mathrm{r}} \mathrm{r}<<1$ and substituting (9), (10) into (4), (8), (2), (3), one can obtain the following expressions for $\mathrm{A}$ and $\mathrm{B}$ :

$$
\begin{gathered}
\mathrm{A}=-\left[\mathrm{i} \pi \mathrm{a} \sigma / 2 \mathrm{Edk}_{0}{ }^{2} \ln \left(\mathrm{v}_{\mathrm{l}} \mathrm{a}\right)\right] \mathrm{p}_{0} \\
\mathrm{~B}=\left[\left(\pi \mathrm{a} \sigma / 2 \mathrm{Edk}_{0}{ }^{3} \ln \left(\mathrm{v}_{\mathrm{l}} \mathrm{a}\right)\right)-\left(\pi \mathrm{a}^{3} / 2 \mathrm{Edk}_{0}\right)\right] \mathrm{p}_{0}
\end{gathered}
$$


It is seen from (11), (12) and (4), (5) that contributions of $\varphi$ and $\psi$ to the ground displacement field are of the same order. Both these potentials are equally important and contribute additively to generating Rayleigh surface waves on the ground surface. However, to demonstrate the effect in principle, we consider here only the contribution of the potential $\varphi$. This essentially simplifies the problem yet allows us to achieve satisfactory estimation for the order of amplitudes of generated Rayleigh waves.

Excitation of longitudinal and shear elastic waves in the elastic half space by potential conical waves in the form (9) has been considered by Jette and Parker $^{8}$. According to this paper, the integral representation of the vertical displacement of the ground surface associated with the excited field has the form

$\mathrm{u}_{\mathrm{z}}=\mathrm{D} \int_{-\infty}^{\infty} \frac{2 \mathrm{k}_{\mathrm{t}}^{2}\left[2\left(\mathrm{k}^{2}+\mathrm{k}_{0}{ }^{2}\right)-\mathrm{k}_{\mathrm{t}}{ }^{2}\right] \exp \left[\mathrm{i}\left(\mathrm{ky}+\mathrm{k}_{0} \mathrm{x}+\mathrm{ih} \sqrt{\mathrm{k}^{2}+\mathrm{k}_{0}{ }^{2}-\mathrm{k}_{1}{ }^{2}}-\omega \mathrm{t}\right)\right]}{\mathrm{F}\left(\sqrt{\mathrm{k}^{2}+\mathrm{k}_{0}{ }^{2}}\right)} \mathrm{dk}$

where $\mathrm{k}$ is a current wavenumber, $\mathrm{D}=-2 \mathrm{iA} / \pi$ is the amplitude coefficient, and $\mathrm{F}\left(\sqrt{\mathrm{k}^{2}+\mathrm{k}_{0}^{2}}\right)=\left[2\left(\mathrm{k}^{2}+\mathrm{k}_{0}^{2}\right)-\mathrm{k}_{\mathrm{t}}^{2}\right]^{2}-4\left(\mathrm{k}^{2}+\mathrm{k}_{0}^{2}\right)\left(\mathrm{k}^{2}+\mathrm{k}_{0}^{2}-\mathrm{k}_{1}^{2}\right)^{1 / 2}\left(\mathrm{k}^{2}+\mathrm{k}_{0}^{2}-\mathrm{k}_{\mathrm{t}}^{2}\right)^{1 / 2}$ is the Rayleigh determinant as a function of $\sqrt{\mathrm{k}^{2}+\mathrm{k}_{0}{ }^{2}}$ (instead of $\mathrm{k}$ in usual notation). Evaluation of the integral (13) in the complex k-plane has been carried out (Jette and Parker ${ }^{8}$ ) by the method of steepest descents. Calculations ${ }^{8}$ have been done with regard to the generation of high-frequency bulk longitudinal and shear elastic waves on the surface, with applications to active acoustic detection of leaks in underground gas distribution lines.

In our consideration we need to investigate generation of Rayleigh surface waves which carry most of the energy of generated low-frequency ground vibrations. To calculate radiated Rayleigh waves we have to take into account the contribution of a residue of the integrand in (13) at $\mathrm{k}$ corresponding to $\mathrm{F}\left(\mathrm{k}^{2}+\mathrm{k}_{0}^{2}\right)=0$, i.e., at $\mathrm{k}=\sqrt{\mathrm{k}_{\mathrm{R}}^{2}-\mathrm{k}_{0}^{2}}$, where $\mathrm{k}_{\mathrm{R}}=\omega / \mathrm{c}_{\mathrm{R}}$ is the Rayleigh wavenumber and $c_{R}$ is the Rayleigh wave velocity. After simple transformations, this results in the following expression for the vertical component of the ground vibration velocity $\mathrm{v}_{\mathrm{z}}=\partial \mathrm{u}_{\mathrm{z}} / \partial \mathrm{t}$ associated with generated Rayleigh waves:

$$
\begin{gathered}
\mathrm{v}_{\mathrm{z}}=-\frac{2 \mathrm{p}_{0} \pi \mathrm{a} \sigma}{\mathrm{Edk}_{0}^{2} \ln \left(\mathrm{v}_{\mathrm{l}} \mathrm{a}\right)} \omega \frac{2 \mathrm{k}_{\mathrm{t}}^{2}\left(2 \mathrm{k}_{\mathrm{R}}^{2}-\mathrm{k}_{\mathrm{t}}^{2}\right)}{\left.\left[\mathrm{F}^{\prime}\left(\mathrm{k}_{\mathrm{R}}\right) / \mathrm{k}_{\mathrm{R}}\right] \sqrt{\mathrm{k}_{\mathrm{R}}^{2}(1+2 \mathrm{i} \gamma)-\mathrm{k}_{0}^{2}}\right)} \exp \left[-\mathrm{h}\left(\mathrm{k}_{\mathrm{R}}{ }^{2}-\mathrm{k}_{1}^{2}\right)^{1 / 2}+\right. \\
\left.\quad \mathrm{ik}_{0} \mathrm{x} \pm \mathrm{i}\left[\mathrm{k}_{\mathrm{R}}^{2}(1+2 \mathrm{i} \gamma)-\mathrm{k}_{0}^{2}\right]^{1 / 2} \mathrm{y}\right]
\end{gathered}
$$

Here $\mathrm{F}^{\prime}\left(\mathrm{k}_{\mathrm{R}}\right)$ is the derivative $\mathrm{dF} / \mathrm{dk}$ of the "usual" Rayleigh determinant $\mathrm{F}(\mathrm{k})=$ $\left(2 \mathrm{k}^{2}-\mathrm{k}_{\mathrm{t}}^{2}\right)^{2}-4 \mathrm{k}^{2}\left(\mathrm{k}^{2}-\mathrm{k}_{\mathrm{l}}^{2}\right)^{1 / 2}\left(\mathrm{k}^{2}-\mathrm{k}_{\mathrm{t}}^{2}\right)^{1 / 2}$ taken at $\mathrm{k}=\mathrm{k}_{\mathrm{R}}$; signs "+" and "-" in the exponential of (14) correspond to the positive and negative values of $y$ respectively, the factor $\exp (-\mathrm{i} \omega \mathrm{t})$ is omitted. In (14) we also have taken into account ground attenuation of Rayleigh waves (where necessary): in the exponential and in the denominator (otherwise a singularity could be expected at $\mathrm{k}_{\mathrm{R}}=\mathrm{k}_{0}$ ). We have accounted for attenuation in a traditional way: via replacing real wavenumber $k_{R}$ by its complex value $k_{R}(1+i \gamma)$, where $\gamma$ is the attenuation constant of the ground ${ }^{3}$. It is assumed that sound waves inside the pipe propagate without attenuation. 


\section{DISCUSSION}

Formula (14) shows that radiation of Rayleigh waves in the ground takes place for $k_{R}>k_{0}$, i.e., for $c_{R}<c_{0}$. Thus, the physical nature of this radiation is similar to that of a sonic boom from supersonic jets or a ground Rayleigh wave boom from superfast trains $\mathrm{s}^{4,5}$. The condition $\mathrm{c}_{\mathrm{R}}<\mathrm{c}_{0}$ may happen quite often since the velocity of sound inside the pipe filled with methane is $450 \mathrm{~m} / \mathrm{s}$ and velocities of Rayleigh surface waves in the ground are typically $300-600 \mathrm{~m} / \mathrm{s}$. It is seen that generated Rayleigh waves are quasi-plane waves propagatifg symmetrically with respect to the $x$-axis at the angles $\Theta=\cos ^{-1}\left(c_{R} / c_{0}\right)$ (Figure 1). If $c_{0}<c_{R}$ then Rayleigh waves are not generated and formula (14) describes the quasi-static field accompanying the sound wave and exponentially decaying with distance $y$ from the pipe.

The presence of the "resonance" expression $\sqrt{\mathrm{k}_{\mathrm{R}}{ }^{2}(1+2 \mathrm{i} \gamma)-\mathrm{k}_{0}{ }^{2}}$ in the denominator of (14) implies that for $k_{R}>k_{0}$ the most efficient generation of Rayleigh waves is expected at $k_{R} \approx k_{0}$, i.e., at $c_{R} \approx c_{0}$. Maximum achievable ground vibration amplitudes in this case are determined by the ground attenuation factor $\gamma$.

We recall that formula (14) describes radiation caused by the time-harmonic sound wave (1) propagating in a pipe. If the wave in a pipe is not timeharmonic, then the frequency spectrum of generated Rayleigh waves is determined as multiplication of (14) by the spectrum of the sound. Without loss of generality, one can assume that in the frequency range of interest $(5-50 \mathrm{~Hz})$ the spectrum of the sound wave in a pipe is approximately uniform with a spectral density $\mathrm{p}_{0}$. In this case, formula (14) gives a straight representation of the ground vibration spectra generated by sound propagating in the pipe.

Numerical calculations of the ground vibration amplitudes $\mathrm{V}=\left|\mathrm{v}_{\mathrm{z}}\right|$ have been carried out according to the formula (14) for the following parameters of the pipe and ground: $\mathrm{a}=0.5 \mathrm{~m}, \mathrm{~d}=0.005 \mathrm{~m}, \mathrm{E}=20 \cdot 10^{10} \mathrm{~N} / \mathrm{m}, \sigma=0.31$ (tempered steel), $\mathrm{c}_{0}=450 \mathrm{~m} / \mathrm{s}, \mathrm{p}_{0}=100 \mathrm{~dB}$ (relative to $2 \sqrt{2} \cdot 10^{-5} \mathrm{~N} / \mathrm{m}^{2}$ ); Poisson ratio of the ground has been taken as 0.25 ; pipe depth $\mathrm{h}$ varied from $0.5 \mathrm{~m}$ to $1.5 \mathrm{~m}$, Rayleigh wave velocity of the ground varied from $400 \mathrm{~m} / \mathrm{s}$ to $500 \mathrm{~m} / \mathrm{s}$, and ground attenuation $\gamma$ varied from 0.005 to 0.015 ; observation distance from the pipe y varied from $25 \mathrm{~m}$ to $100 \mathrm{~m}$.

Figure 2 shows Rayleigh wave ground vibration spectra for three values of pipe-depth: $\mathrm{h}=0.5,1.0$ and $1.5 \mathrm{~m}$ (curves V1, V2, and V3 respectively). Here $c_{R}=440 \mathrm{~m} / \mathrm{s}, \mathrm{y}=50 \mathrm{~m}$ and $\gamma=0.005$. One can see that generated spectra have maxima with magnitudes and locations dependent on $h$. The lower the $h$ values, the higher the central frequencies and the larger the magnitudes.

Figure 3 represents ground vibration amplitudes as functions of Rayleigh wave velocity in the ground $c_{R}$ for three values of ground attenuation $\gamma=0.005$, 0.010 , and 0.015 (curves V1, V2, and V3 respectively). Distance y has been chosen as $50 \mathrm{~m}$, pipe depth $\mathrm{h}$ was $1 \mathrm{~m}$, and frequency $\mathrm{f}$ as equal to $20 \mathrm{~Hz}$. One can see that at $c_{R}$ approaching $c_{0}$ from the left-hand side a resonance increase of generated ground vibrations occurs. For $c_{R}>c_{0}$ a quick drop in amplitudes takes place characterising exponential decay of the accompanying quasi-static field with distance $y$.

\section{CONCLUSIONS}

It has been shown that one of the possible causes of low-frequency hum may be related to ground vibrations propagating to buildings as surface Rayleigh waves. These waves may be generated by buried underground gas or petrol pipes in which turbulent flows of gas or liquid generate sound waves 


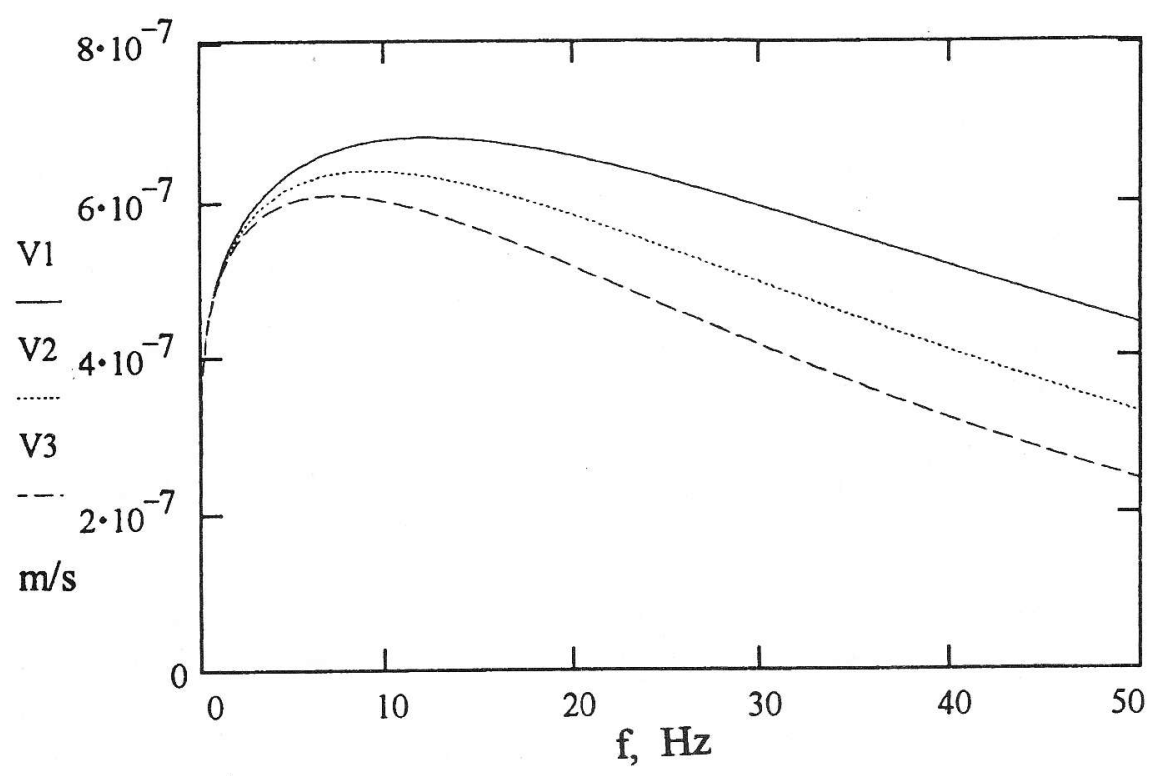

Figure 2. Ground vibration spectra for different pipe-depths.

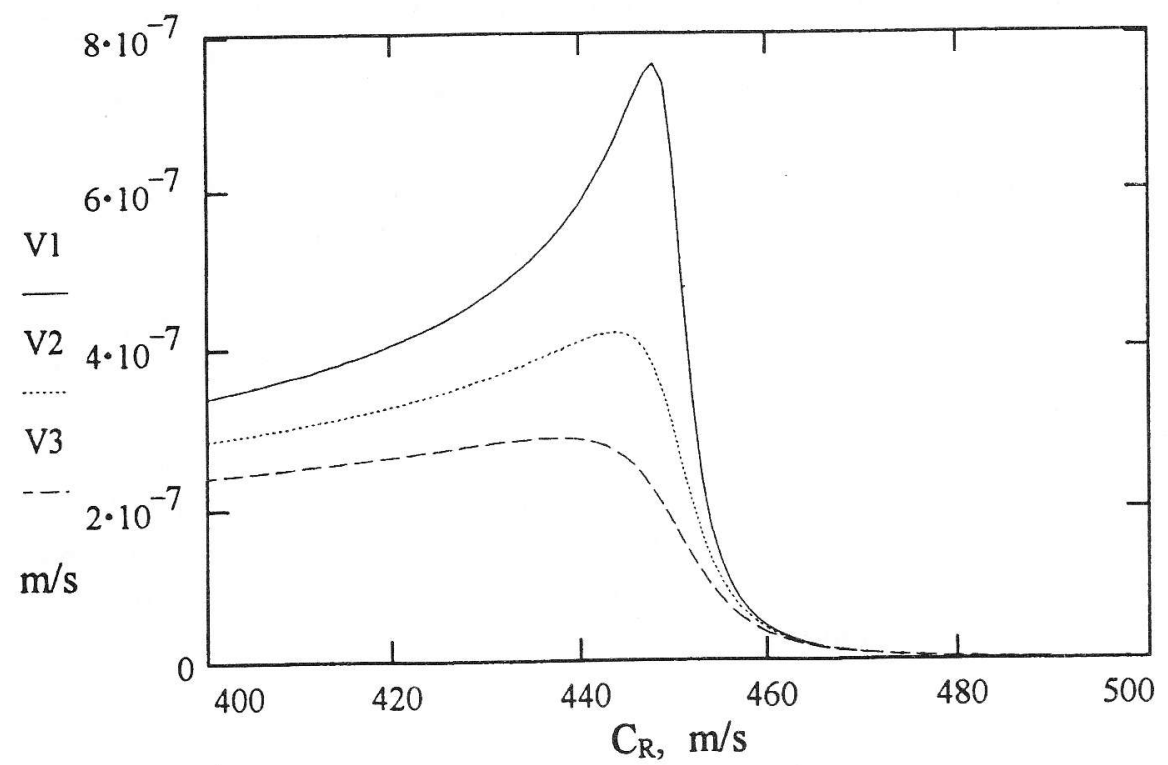

Figure 3. Ground vibration amplitudes as functions of Rayleigh wave velocity in the ground.

propagating in a pipe-line as in a waveguide. Such a generation takes place if the velocities of sound $\mathrm{c}_{0}$ inside the pipes $(450 \mathrm{~m} / \mathrm{s}$ for methane) are higher than the velocities of Rayleigh surface waves $c_{R}$ in the ground. Especially large resonance increase occurs for $c_{0}$ slightly higher than $c_{R}$. The physical nature of this phenomenon is similar to that of sound boom from supersonic jets or that of recently predicted Rayleigh ground wave boom from superfast trains.

The results of this paper are based on the simplified model which does not take into account the radiation of shear waves or the influence of layered structure of the ground. Therefore, they should be considered as preliminary ones giving merely a qualitative picture of the phenomenon. Further theoretical investigation is required to provide a more detailed quantitative description taking account of layered structure of the ground and particular mechanisms of 


\section{GENERATION OF LOW-FREQUENCY GROUND VIBRATIONS}

sound excitation in pipes.

\section{REFERENCES}

1. Tempest, W. Journ. Low Frequency Noise and Vibration, Vol. 8, 45 (1989).

2. Sargent, J.W. Report, Building Research Establishment, UK, Garston (October 1994).

3. Krylov, V. and Ferguson, C. Applied Acoustics, Vol. 42, 199 (1994).

4. Krylov, V.V. Journ. de Phys. IV, Vol. 4 (C5), 769 (1994).

5. Krylov, V.V. Applied Acoustics, Vol. 44, 149 (1995).

6. Junger, M.C. and Feit, D. Sound, Structures, and Their Interaction, Acoust. Soc. Amer., New York (1993).

7. Jette, A.N., Morris, M.S. Murphy, J.C. and Parker, J.G. Materials Evaluation, Vol. 35, 90 (1977).

8. Jette, A.N. and Parker, J.G. Journ. Sound and Vibration, Vol. 67, 523 (1979). 